\title{
VENOUS ENGORGEMENT AND INTRAOSSEOUS HYPERTENSION IN OSTEOARTHRITIS OF THE HIP
}

\author{
Carl C. Arnoldi, Håkan Linderholm and Herbert Müssbichler, \\ UMEÅ, SWEDEN \\ From the Departments of Orthopaedic Surgery, Clinical Physiology and Diagnostic Radiology, \\ University Hospital, Umeai
}

Many investigators have considered that local vascular changes may be important in the etiology and pathogenesis of degenerative arthritis, but opinions differ as to the nature of these changes. Several authors have suggested that osteoarthritis is accompanied or preceded by a state of ischaemia of subchondral and juxtachondral bone (Wollenberg 1909; Goldhaft, Wright and Pemberton 1930; Phemister 1940; Cheynel 1947; Pridie 1952). This conception was challenged by Harrison, Schajowicz and Trueta (1953). They found in injection studies on cadavers a hyperplasia of intraosseous arteries in the femoral head, and on the basis of these observations they assumed that the arterial inflow to the weight-bearing cancellous bone was increased in osteoarthritis.

TABLE I

Age and Stx Distribution in Two Series of Patients with Osteoarthritis of the Hip

\begin{tabular}{|lcccc|}
\hline & $\begin{array}{c}\text { Number of } \\
\text { patients }\end{array}$ & $\begin{array}{c}\text { Average age: } \\
\text { Mean and range } \\
\text { (years) }\end{array}$ & Men & Women \\
\hline $\begin{array}{l}\text { Series I } \\
\text { Unilateral osteoarthritis }\end{array}$ & 15 & $\begin{array}{c}61 \cdot 9 \\
(45-72) \\
62 \cdot 9\end{array}$ \\
$\begin{array}{l}\text { Series II } \\
\text { Unilateral measurement }\end{array}$ & 15 & 3 & 7 & 12 \\
\hline \multicolumn{1}{c|}{ Total } & 30 & $\begin{array}{c}62 \cdot 3 \\
(36-72)\end{array}$ & 10 & 20 \\
\hline
\end{tabular}

In recent years investigations by means of intraosseous phlebography have provided evidence of disturbed venous outflow from the femoral head and neck in patients with osteoarthritis of the hip, and from the epiphysis and metaphysis of the distal femur in patients with osteoarthritis of the knee (Mériel, Ruffié and Fournié 1955; Helal 1962; Wardle 1964; Phillips 1966).

These apparently conflicting conceptions of the nature of the vascular changes in osteoarthritis reflect the need for further information. The present paper is concerned with the problems of venous drainage from juxtachondral bone in patients with osteoarthritis of the hip. The methods of investigation were intraosseous phlebography and measurements of intraosseous pressure.

\section{MATERIAL}

Two series of patients were examined. Table I shows the age and sex distribution in the two series.

The first series consisted of fifteen patients with unilateral osteoarthritis. In these patients the intraosseous pressure of the femoral neck was measured on both sides and the pressure in the femoral vein was determined simultaneously. Bilateral intraosseous phlebography was also done.

vol. 54 B, No. 3, AUGUST 1972 
In the second series the intraosseous pressures of the femoral head and neck on one side were measured simultaneously in fifteen patients undergoing operation for severe osteoarthritis. Vein pressures were not determined in this series. No patient with signs and symptoms of heart failure was included.

Table II shows the clinical features and radiographic findings in the patients of the two series.

TABLE II

Clinical. and Radiographic Features in Both Series of Patients

\begin{tabular}{|c|c|c|c|c|c|}
\hline \multirow{2}{*}{\multicolumn{3}{|c|}{$\begin{array}{l}\text { Clinical and radiographic } \\
\text { features }\end{array}$}} & \multicolumn{2}{|c|}{ Series I } & \multirow{3}{*}{$\begin{array}{c}\begin{array}{c}\text { Series II } \\
\text { Arthritic }\end{array} \\
15\end{array}$} \\
\hline & & & \multirow{2}{*}{$\frac{\text { Normal }}{15}$} & \multirow{2}{*}{$\begin{array}{c}\text { Arthritic } \\
15\end{array}$} & \\
\hline Number of hips & . & . & & & \\
\hline Pain on passive $m$ & ovement & . & 0 & 15 & 15 \\
\hline Pain on walking & . & . & 0 & 15 & 15 \\
\hline Rest pain . & . & . & 0 & 9 & 11 \\
\hline \multicolumn{6}{|c|}{ Restriction of joint movement: } \\
\hline Rotation . & . & . & $\mathbf{0}$ & 15 & 15 \\
\hline Abduction and & adduction & . & 0 & 13 & 15 \\
\hline Flexion and ex & tension & . & $\mathbf{0}$ & 12 & 13 \\
\hline \multicolumn{6}{|l|}{ Osteophytes: } \\
\hline Femoral head & . & - & 1 & 14 & 15 \\
\hline Acetabulum & . & . & 2 & 11 & 13 \\
\hline \multicolumn{6}{|l|}{ Joint space: } \\
\hline Normal & . & - & 15 & 1 & $\mathbf{0}$ \\
\hline Decreased & . & . & 0 & 14 & 15 \\
\hline \multicolumn{6}{|c|}{ Juxtachondral sclerosis: } \\
\hline Femoral head & . & $\cdot$ & $\mathbf{0}$ & 13 & 12 \\
\hline Acetabulum & . & . & $\mathbf{0}$ & 11 & 11 \\
\hline \multicolumn{6}{|l|}{ Cysts: } \\
\hline Femoral head & . & & 0 & 12 & 9 \\
\hline Acetabulum & . & . & 0 & 8 & 10 \\
\hline Displacement & . & . & 0 & 8 & 9 \\
\hline
\end{tabular}

METHODS

VENOUS AND INTRAMEDULLARY PRESSURE MEASUREMENTS

In the first series pressure differences between normal and arthritic hips were examined. In the second series measurements were done to determine possible pressure differences between the femoral head and neck.

First series: Bilateral examination of intraosseous and of intravenous pressures in patients with unilateral arthritis-The patient was placed supine on an operation table with television screening equipment under general anaesthesia with intermittent positive pressure breathing. 
The central x-ray beam was perpendicular to the surface of the operation table. Through skin punctures, specially constructed conical needles (made by AB Stille-Werner, Stockholm) 15 centimetres long, with an external diameter of 4.55 millimetres at the tip and a lumen measuring 2.60 millimetres, were introduced into the proximal parts of the two femurs through the lateral aspect of the trochanter. In order to ensure an intramedullary position of the needle the tip was placed in the base of the femoral neck and not in the femoral head.

Polyethylene catheters (P160) were inserted into the internal saphenous veins through incisions at the ankle. The end of each catheter was advanced to the level of the point of measurement of intraosseous pressure - that is, immediately proximal to the junction of the internal saphenous and femoral veins. In the first five patients examined, bilateral measurements of vein pressure were taken; because no differences between the two sides were observed, the pressure in the femoral vein was measured on one side only in the remaining cases.

The catheter in the vein and the needles in the bone marrow were connected to infusion drips of saline that were continued -except during the periods of pressure measurements-until the end of the examination.

Second series: Unilateral examination of intramedullary pressure in the femoral head. and neck in patients with arthritis-The patients in this series were examined on the operation table before osteotomy or arthro-

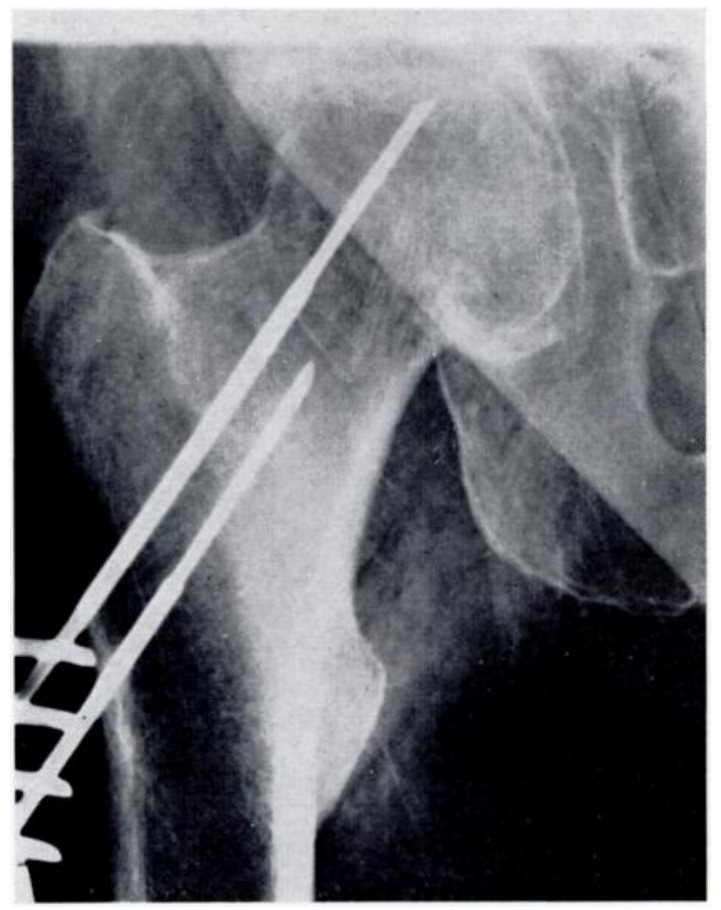

Fig. 1

Position of the two needles used for measurement of intraosseous pressure in the femoral head and neck (second series). plasty. During the pressure examination they were lying nearly horizontal. General anaesthesia with intermittent positive pressure breathing was used. Two metal needles (made by AB Stille-Werner, Stockholm) with an outside diameter of 2 millimetres at the tip and a lumen measuring 1.4 millimetres were inserted into the proximal part of the femur from the lateral aspect of the trochanter. A small incision was used to expose the periosteum of this region. Television x-ray screening was used for frontal and lateral views as well as film exposures. One needle, 17 centimetres long, was placed in the femoral head; the other, 11 centimetres long, was placed with its point in the neck (Fig. 1).

The needles were flushed out with 0.9 per cent saline solution containing 50 milligrams of heparin per 100 millilitres in order to ensure a free flow through the needles into the bone marrow. Saline was then infused through each needle (Fig. 2) and the infusion was continued -except during periods of pressure measurements - until the end of the examination.

Pressure measurements-The same technique was used in both series. Polyethylene catheters (PE90) were fitted to the needles in the bone marrow and these tubes and the catheter in the vein (first series) were connected to a pressure recording system for simultaneous recording of the pressure curves by means of a Mingograph (Elema) with paper speed of 5 millimetres per second (Fig. 2).

The pressure recording system was found to be linear within the range of measurements and-tested with a sine wave pressure of varying frequency-the amplitude was correctly recorded to about $15 c$ per second.

VOL. 54 B, NO. 3, AUGUST 1972 
The mid-axillary plane at the level of the fourth costal insertion at the sternum was chosen to indicate heart level, which was the reference level for all pressures measured.

\section{INTRAOSSEOUS PHLEBOGRAPHY}

Intraosseous phlebography was done bilaterally on the patients of the first series through the needles previously introduced for pressure measurements. The patients were examined in a supine horizontal position without anaesthesia. Eight millilitres of Isopaque Cerebral ${ }^{\circledR}$ were injected on each side through the needle into the bone marrow. The injection time was twenty to forty seconds. The first film was taken during the injection of contrast material. Further films were exposed thirty seconds and one, three, six, twelve, twenty and thirty minutes later. Occasionally, a last exposure was made after fifty minutes. Antero-posterior radiographs of both limbs were taken simultaneously. The focus-film distance was 120 centimetres. The films were exposed at 70 to 85 kilovolts and 64 milliamps with an exposure time of $0 \cdot 1$ second.

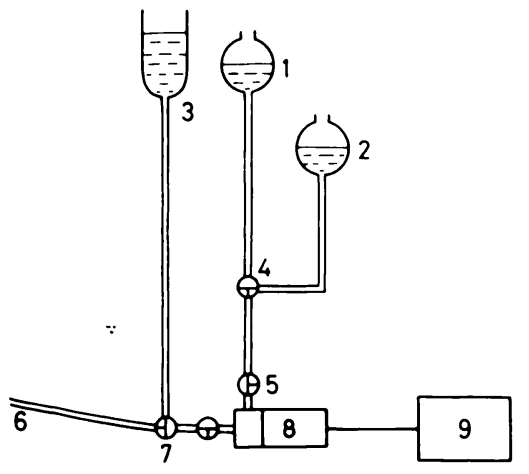

Fig. 2
FIG. 2

Schematic representation of the pressure-manometer system. The standard pressure level (1), usually 68 centimetres (corresponding to 50 millimetres $\mathrm{Hg}$ ) above that of the reference pressure (2), was the same for the three (two) manometer systems used. A container (3)-one for each needle-manometer system-was for infusion of saline. By means of three-way stop-cocks (4 and 5$)$ the manometer could be connected to the pressure reference system and at the same time disconnected from the polyethylene tubing (6) by means of another three-way stop-cock (7), which then allowed saline to flow slowly into the bone marrow. The manometer, a mechano-electrical transducer (8) and the amplifier unit (9) were connected to the Mingograph recorder.

In the analysis of the phlebographic series of exposures the "emptying time" was taken as the number of minutes between the injection of contrast medium and the first film completely free from contrast medium. The emptying time was found for intraosseous as well as extraosseous veins. In the latter case isolated traces of contrast medium in valvular sinuses were ignored.

\section{RESULTS}

\section{PRESSURE MEASUREMENTS}

First series: Simultaneous bilateral measurements of pressure in the femoral neck in patients with unilateral arthritis and measurements of pressure in the femoral vein.

Femoral vein-In the first five patients examined the pressure in the femoral vein was measured on both sides. The results from these cases showed, however, that the pressures from the normal and the affected side were equal (mean difference $=0 \cdot 2$ millimetre of mercury). In the remaining ten patients the pressure in the femoral vein was therefore measured on one side only, in the unaffected limb in six patients, on the arthritic side in four patients.

The femoral vein pressure ranged between 6.5 and 15.6 millimetres of mercury, with a mean pressure of 11.9 millimetres of mercury (Table III).

Intraosseous pressure of the femoral neck-The pressure tracings were always pulsatile and the pulse pressure was higher on the arthritic side than in the normal limb (Table III). The intraosseous pressure was always higher than the pressure in the femoral vein. In the normal hip the difference between intramedullary and venous pressure ranged between 2.3 and 17 millimetres of mercury, with a mean difference of 6.8 millimetres of mercury (Table III). 
TABLE III

Pulse Pressure Amplitude, Intraosseous Pressure of thf. Femoral Neck and Femoral Vein Pressure in Millimetres of Mercury in Fifteen Patients with Unilateral Osteoarthritis (Series I)

\begin{tabular}{|c|c|c|c|c|c|}
\hline Site of measurement & $\begin{array}{c}\text { Unaffected } \\
\text { hip joint } \\
\text { (15 cases) } \\
\text { Mean and range }\end{array}$ & $\begin{array}{l}\text { Standard } \\
\text { deviation }\end{array}$ & $\begin{array}{c}\text { Arthritic } \\
\text { hip joint } \\
\text { (15 cases) } \\
\text { Mean and range }\end{array}$ & $\begin{array}{l}\text { Standard } \\
\text { deviation }\end{array}$ & $\begin{array}{l}\text { Difference } \\
\text { between } \\
\text { arthritic and } \\
\text { unaffected hip }\end{array}$ \\
\hline Intramedullary pulse pressure amplitude & $\stackrel{4}{(2-11)}$ & $2 \cdot 9$ & $\begin{array}{c}6 \cdot 8 \\
(2-18)\end{array}$ & $5 \cdot 2$ & $2 \cdot 8 * *$ \\
\hline Neck pressure & $\begin{array}{c}18 \cdot 7 \\
(13 \cdot 5-25 \cdot 3)\end{array}$ & $3 \cdot 6$ & $\begin{array}{c}48 \cdot 4 \\
(27 \cdot 8-74 \cdot 8)\end{array}$ & $16 \cdot 3$ & $29 \cdot 7 * * *$ \\
\hline Femoral vein pressure & $\begin{array}{c}11.9 \\
(6.5-15 \cdot 6)\end{array}$ & $2 \cdot 5$ & $\begin{array}{c}11 \cdot 9 \\
(6 \cdot 5-15 \cdot 6)\end{array}$ & $2 \cdot 5$ & \\
\hline
\end{tabular}

Mean difference between intramedullary neck pressure and femoral vein pressure in unaffected hips=+6.8 millimetres of mercury $(P<0.001)$

${ }^{*}-0.01<\mathrm{P}<0.05 ;{ }^{* *}=0.001<\mathrm{P}<0.01 ; * * *=\mathrm{P}<0.001 ; \mathrm{P}$ is the possibility that the difference is caused by chance.

The intraosseous pressure in the arthritic hip was higher than in the healthy hip (Fig. 3). The difference varied within rather wide limits (11.9 to 57.5 millimetres of mercury), with a mean difference of 29.7 millimetres of mercury (Table III).

Second series: Simultaneous measurements of intramedullary pressures of the head and the neck of the femur in arthritic hips-Pulsatile pressure tracings were always obtained from both points of measurement. The average pulse pressure in the head was somewhat greater than that in the neck (Table IV), but the difference was not statistically significant. The intraosseous pressure of the femoral neck was of the same order as that observed in the arthritic joints of the first series (Tables III and IV). The intraosseous pressure in the femoral head was always greater than the pressure in the femoral neck (Fig. 4 and Table IV).

TABLE IV

Intramedullary Pressures in Millimetres of Mercury of the Femoral Head and Neck Measured Simultaneously in Patients with Osteoarthritis (Series II)

\begin{tabular}{|l|c|c|c|c|c|c|}
\hline & $\begin{array}{c}\text { Number of } \\
\text { patients }\end{array}$ & $\begin{array}{c}\text { Femoral head } \\
\text { Mean and range }\end{array}$ & $\begin{array}{c}\text { Standard } \\
\text { deviation }\end{array}$ & $\begin{array}{c}\text { Femoral neck } \\
\text { Mean and range }\end{array}$ & $\begin{array}{c}\text { Standard } \\
\text { deviation }\end{array}$ & Difference \\
\cline { 1 - 6 } Intramedullary pulse pressure & 15 & $\begin{array}{c}5 \cdot 8 \\
(1-29)\end{array}$ & $7 \cdot 3$ & $\begin{array}{c}4 \cdot 4 \\
(1-17)\end{array}$ & $4 \cdot 2$ & $1 \cdot 4$ \\
Intramedullary pressure & 15 & $\begin{array}{c}54 \\
(30 \cdot 9-88 \cdot 7)\end{array}$ & $16 \cdot 6$ & $\begin{array}{c}43 \cdot 1 \\
(23-66 \cdot 7)\end{array}$ & $13 \cdot 9$ & $10 \cdot 8^{* * *}$ \\
\hline
\end{tabular}

$$
* * *=\mathbf{P}<0.001 \text {. }
$$

\section{INTRAOSSEOUS PHLEBOGRAPHY}

The healthy hip-The veins draining the femoral head and neck usually accompany the arteries. Blood leaves the femoral head and neck through superior and inferior retinacular vessels draining to the medial circumflex and gluteal veins, while the trochanteric region is drained to the lateral circumflex vein (Figs. 5 to 10). The medial and lateral circumflex veins usually empty into the deep femoral vein, but communications to the obturator veins are not uncommon. Veins leaving the femoral head through the ligament of the femoral head were never observed in these series.

vol. 54 B, No. 3, AUGUST 1972 
In normal hips the injected contrast material leaves the intramedullary space within three to six minutes (Table V). The extraosseous veins are therefore well filled, and details such as valves are clearly seen (Figs. 5 to 10 ).

Filling of intramedullary vessels was observed only in a small circumscribed area around the tip of the needle. The intraosseous channels of this area formed a fine-meshed network of minute vessels (Figs. 5 and 6). In all cases the contrast medium had disappeared from the intramedullary and extraosseous veins within six minutes after the injection (Table V), except for occasional retention of contrast material in the valvular sinuses of the extraosseous veins (Fig. 8).

The arthritic hip-Generally, the phlebographs of arthritic hips were characterised by partial or complete absence of extraosseous veins that normally drain the femoral head and neck. Foveolar veins were never observed. The retinacular vessels had often disappeared completely and the medial circumflex veins were narrowed or missing in most of the cases (Figs. 5 to 10). The filling of remaining extraosseous vessels was generally poor.

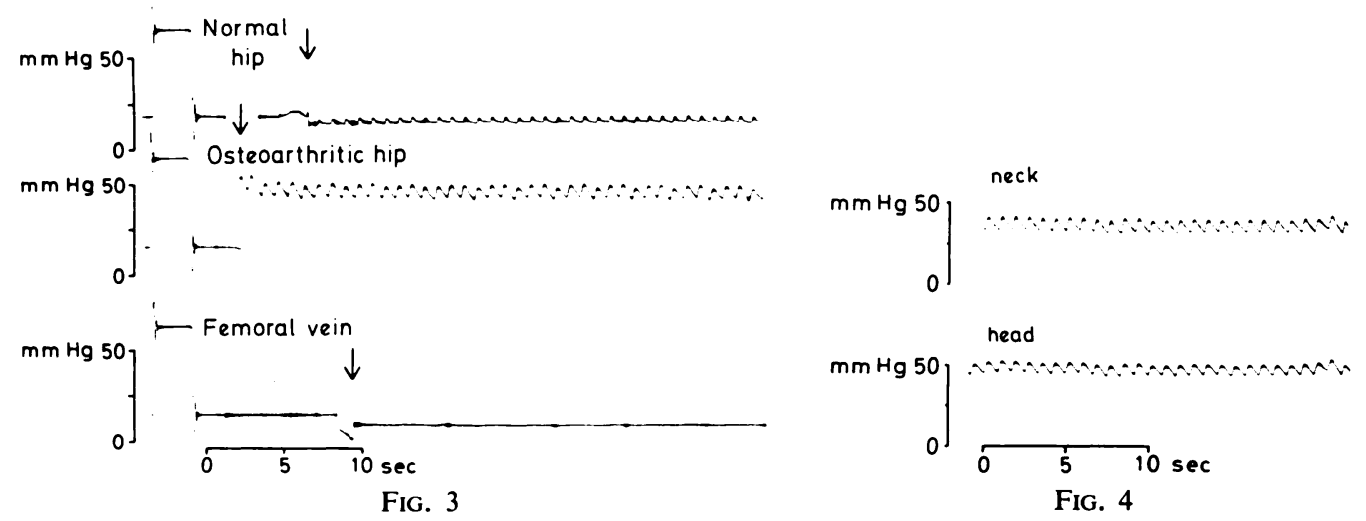

Figure 3-Bilateral measurements of intraosseous pressure in the femoral neck with simultaneous recording of femoral vein pressure. Patient with unilateral osteoarthritis (first series). Figure 4 -Simultaneous recordings of the intraosseous pressures of the femoral head and neck from hip joint with osteoarthritis (second series).

The area of small intraosseous vessels around the tip of the needle was enlarged. The vessels of this area were generally wider and more irregular than the corresponding vessels on the unaffected side. In all cases tortuous and dilated intraosseous vessels filled with contrast medium were seen extending from the region of the injection site distally towards or into the diaphysis (Figs. 5 to 12). In cases of advanced arthritis drainage from the femoral head and neck took place solely through these descending intramedullary vessels to perforating veins emerging from the proximal half of the femoral shaft to join branches of the deep femoral vein or superficial veins on the lateral aspect (Figs. 9 and 10).

As a rule the extraosseous veins were empty of contrast material within a few minutes after the injection. However, the drainage of contrast material from the intramedullary vessels was delayed, compared to the unaffected side (Figs. 11 and 12). The intraosseous vessels generally remained filled with contrast medium as long as the observation continued (Table V).

\section{DISCUSSION}

Factors influencing intramedullary pressure- In our measurements of intramedullary pressure fairly thick needles were driven forcefully into the cancellous bone marrow. The tip of the needle probably ends up by lying in an artificial pool of blood caused by a breakdown of cancellous trabeculae with laceration of adjacent blood vessels. Probably the blood in this pool is in continuity with the sinusoids of the cancellous bone marrow and also with lacerated small arteries and veins. 


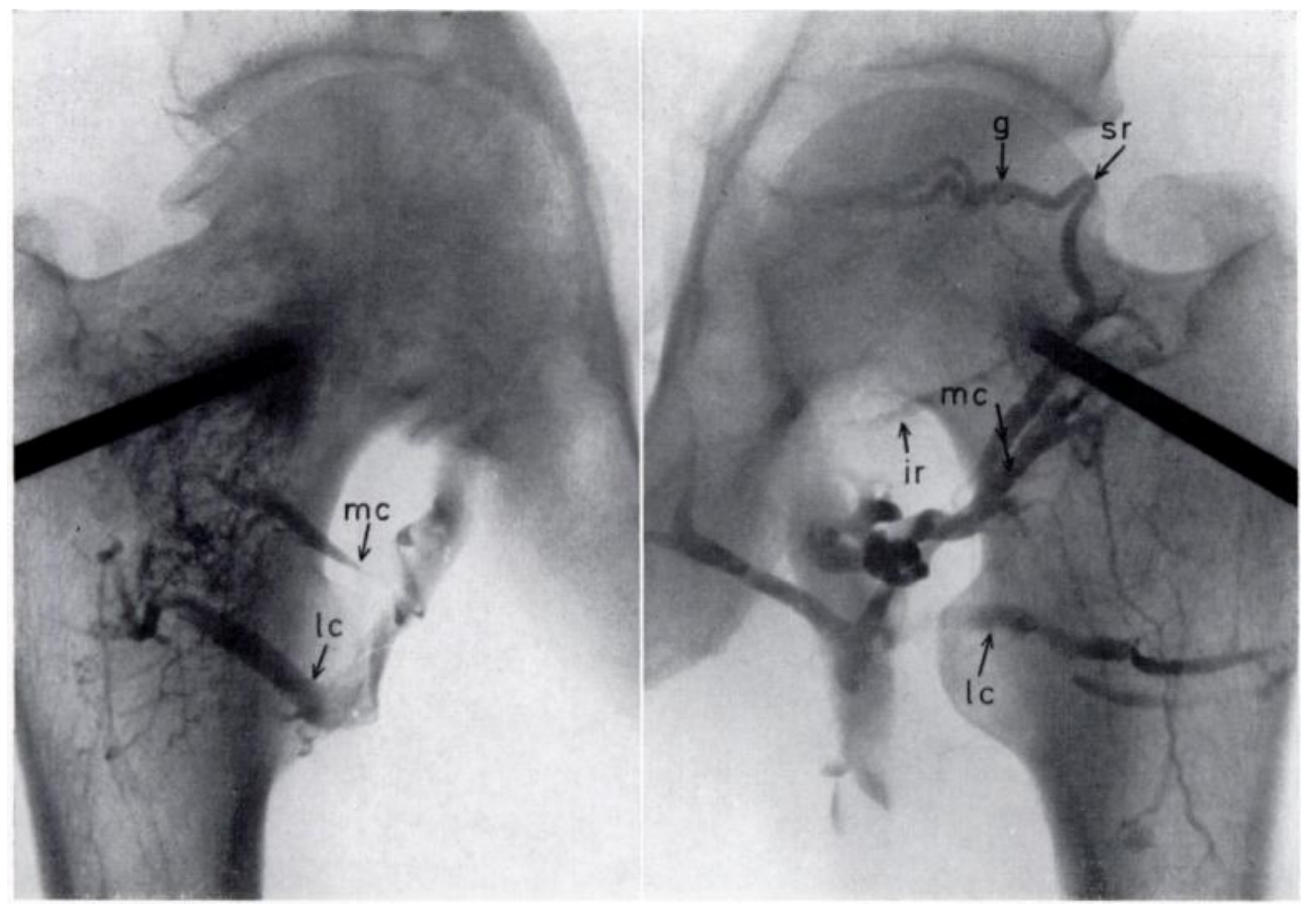

FIG. 5

Fig. 6

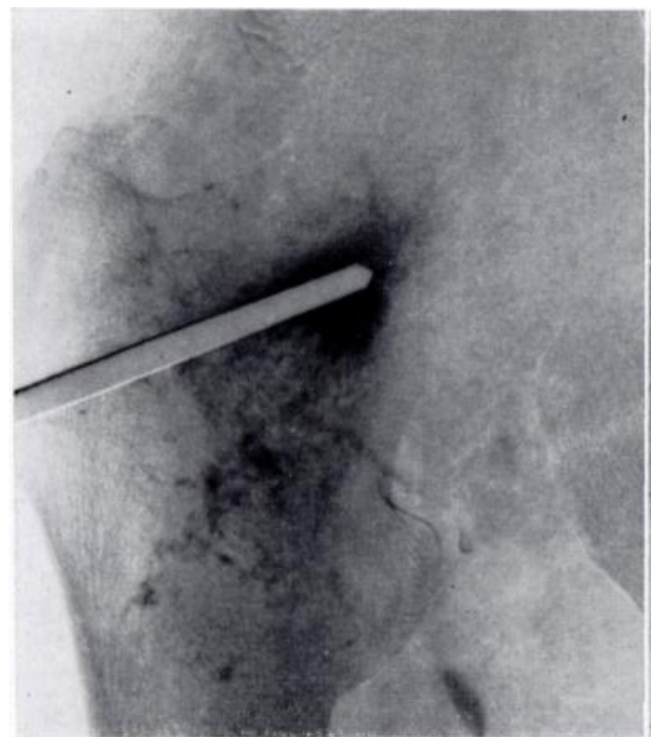

Fig. 7

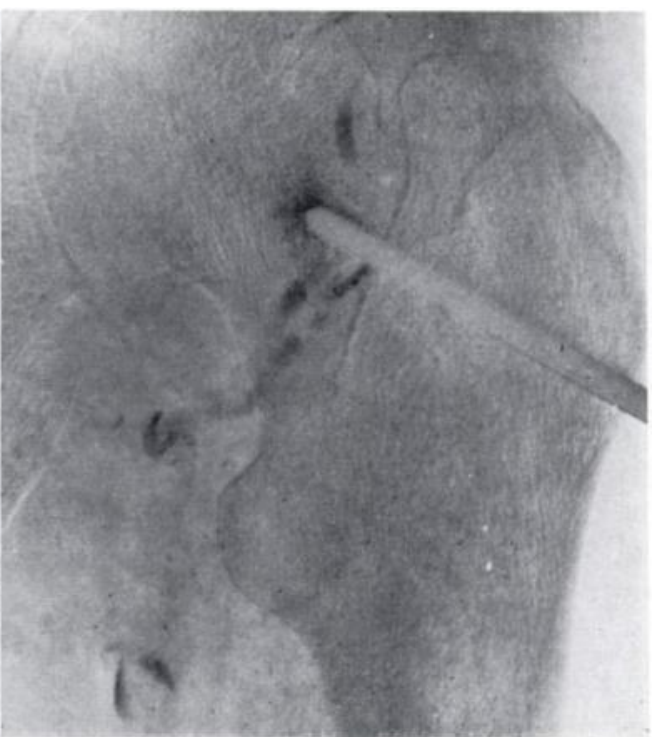

Fig. 8

Bilateral simultaneous phlebography in a patient with healthy left hip and osteoarthritis of the right hip. Figure 5-Phlebograph from arthritic hip thirty seconds after injection of contrast material. Zone of contrast medium around needle tip considerably enlarged, with widened intraosseous vessels. Drainage through extraosseous vessels much reduced: superior and inferior retinacular veins absent; the single medial circumflex vein $(\mathrm{mc})$ narrowed. The only intact drainage channel is the lateral circumflex vein (lc). Figure 6-Phlebograph of normal hip obtained thirty seconds after injection. Intraosseous contrast material observed in a small zone around the needle tip. Drainage through superior retinacular vein (sr) to a gluteal vein (g), through inferior retinacular vein (ir), two medial circumflex veins (mc) and a lateral circumflex vein (lc). Figures 7 and 8 are subtraction phlebographs of the same exposure series taken 1.5 minutes after the injection. On the normal side (Fig. 8) only a very small amount of contrast material is left intraosseously around the tip of the needle. On the arthritic side (Fig. 7) most of the contrast material is remaining intraosseously, indicating that drainage is considerably retarded.

(Contrast material was visible in intraosseous vessels until twenty minutes after the injection.)

vol. 54 B, No. 3, AUGUST 1972 


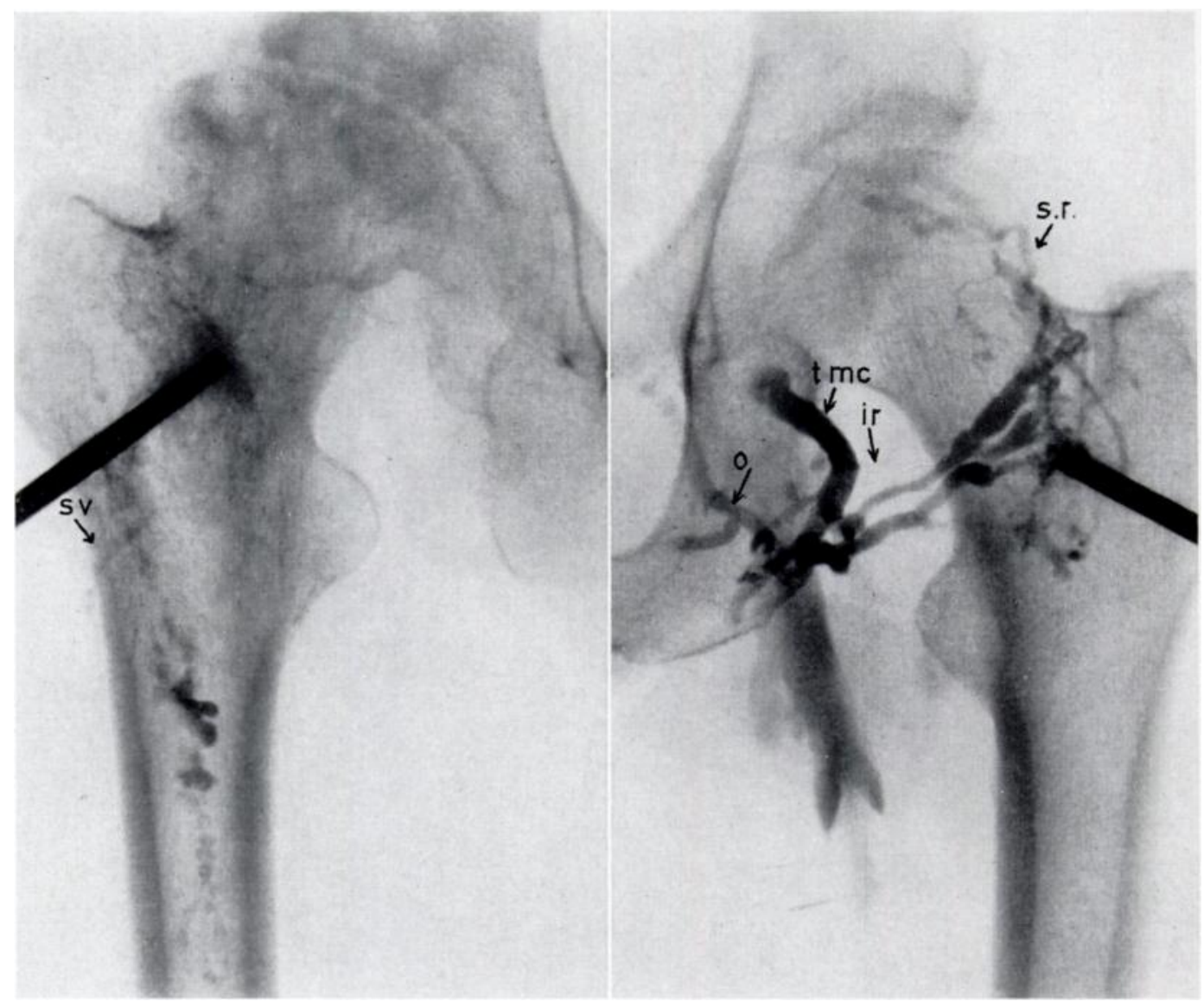

FIG. 9

Fig. 10

Intraosseous phlebographs from normal left hip (Fig. 10) and from the right hip with severe osteoarthritis (Fig. 9) exposed thirty seconds after bilateral injection of 8 millilitres Isopaque Cerebral. In the normal hip the contrast material leaves the intraosseous space without noticeable filling of intraosseous vessels. Drainage takes place through superior retinacular veins (s.r.) to gluteal veins and via two medial circumflex veins to femoral and obturator (o) veins, as well as through inferior retinacular vein (ir) emptying into the trunk of the medial circumflex vein $(\mathrm{tmc})$. These extraosseous vessels are well filled and the arrangement of valves clearly visible. In the right hip (Fig. 9) the contrast material is collected in enlarged, tortuous intraosseous vessels, extending from the base of the neck to the border between the upper and middle third of the diaphysis. The only connection between intraosseous and extraosseous veins to be demonstrated are slender vessels at the lateral aspect of the proximal part of the diaphysis, draining contrast material to superficial veins (sv).

In normal cancellous bone of the femoral neck the blood pressure in the pool was 7 ( 2.5 to 17$)$ millimetres of mercury above the pressure in large extraosseous veins. This elevated pressure level may be caused by an increased inflow of blood from ruptured intraosseous arteries or arterioles. It may be representative of a localised high pressure zone around the tip of the needle, but our findings from pressure measurements during infusion of fluid into cancellous bone of normal and arthritic hips and in fractures of the femoral neck (Arnoldi and Linderholm 1972) make it likely that an increase of pressure would be distributed fairly widely throughout the cancellous bone within the cortex.

Alternatively, the pressure measured may be representative of the pressure in non-injured sinusoids and intraosseous veins of cancellous bone. The rise above the level of extraosseous venous pressure would then be due mainly to a comparatively high and individually somewhat variable resistance to outflow of blood across the cortex (Fig. 13).

Compression of the arteries supplying the bone causes a fall of intraosseous pressure (Süsse 1956, Azuma 1964). The fall in pressure approximately corresponds to the difference 


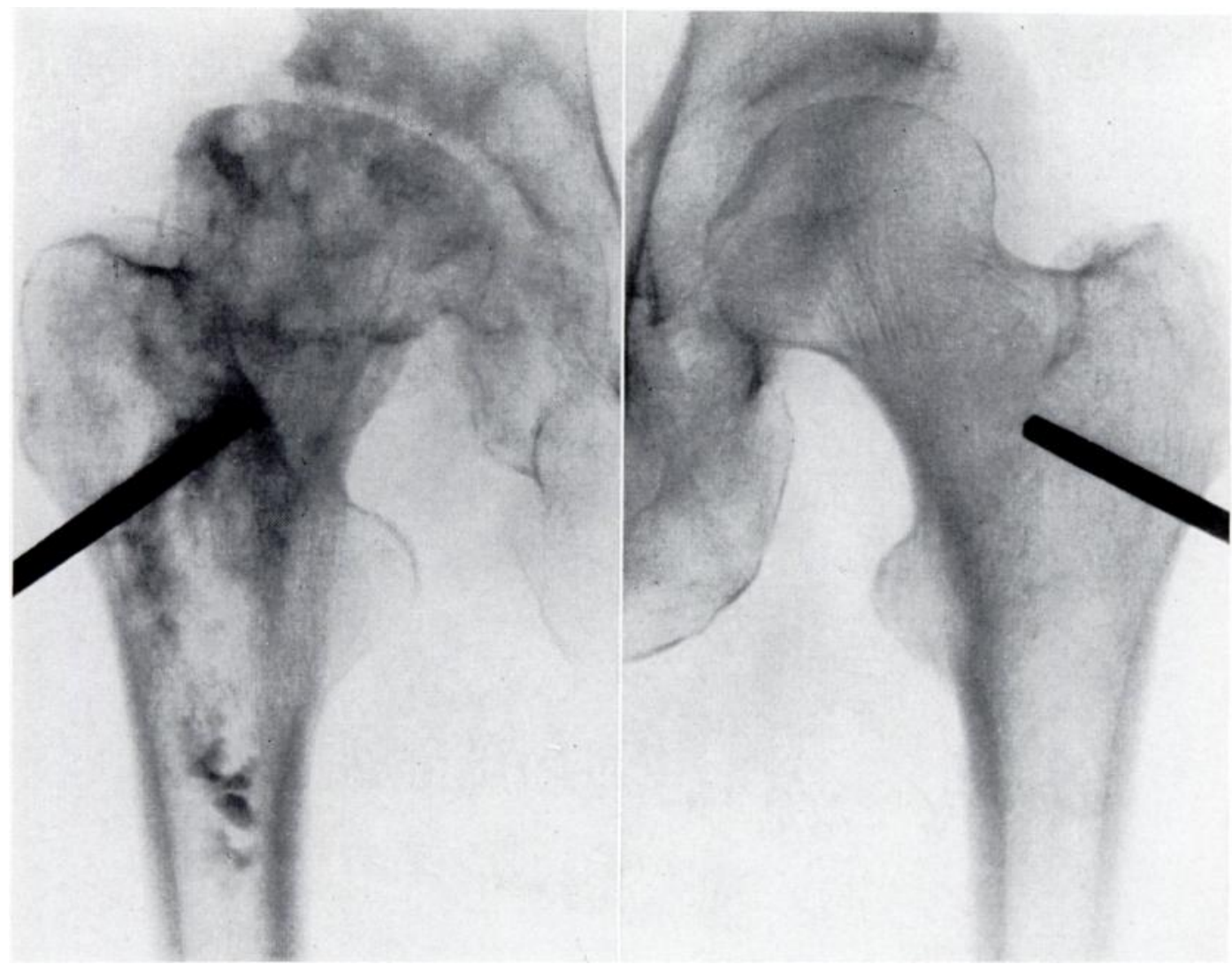

FIG. 11

FiG. 12

Intraosseous phlebographs from the same patient as in Figures 9 and 10 exposed thirty minutes after the injection. In the left hip (Fig. 12) there is no sign of contrast material in extraosseous or intraosseous veins. (Complete drainage was noted three minutes after the injection). In the right or arthritic hip (Fig. 11) large quantities of contrast medium remain in the intraosseous space. No filling of extraosseous veins.

between intramedullary pressure and the pressure in the extraosseous veins (Arnoldi and Linderholm 1972).

Compression of the veins draining the bone is accompanied by a rise of intraosseous pressure. Earlier investigations have shown that while the intraosseous pressure is very little influenced by changes in arterial pressure under normal conditions, great pressure variations may be caused by changes in the conditions for the venous drainage from bone (Arnoldi and Linderholm 1966, 1971).

The most conspicuous difference between the phlebographs from healthy and from arthritic hips was the change in the pathways of venous drainage from the femoral head and neck. The extraosseous veins normally draining the head-that is, the retinacular veinsseemed to be the first to disappear from the phlebograph in osteoarthritis. In advanced arthritis even the circumflex veins and the venous plexus of the intertrochanteric fossa had disappeared. In such cases the contrast medium passed from the femoral head and neck down into the diaphysis through intramedullary veins, occasionally visible as far distally as the lower part of the shaft; the only connections between intraosseous and extraosseous veins were the set of perforating veins from the femoral shaft draining into branches of the deep femoral or superficial veins.

The highest intraosseous pressures were observed in patients in whom the drainage system was most deranged. There seemed to be an association between high intraosseous pressure and delayed emptying of contrast material from the medullary space. The findings suggest 
that the intraosseous hypertension observed in osteoarthritis is caused by increased resistance to venous outflow across the cortex from the cancellous bone marrow of the proximal part of the femur. When osteotomy or a fenestration operation was done in the proximal part of the femur the intraosseous pressure fell immediately (Arnoldi, Lemperg and Linderholm 1971).

TABLE V

Emptying Time for Contrast Medium Injected

INTRAOSSEOUSLY INTO THE FEMORAL NECK DURING

Bilateral Phlebography of Thirteen Patients

With UNilateral ArThritis (from Series I)

\begin{tabular}{|c|c|c|}
\hline \multirow{2}{*}{$\begin{array}{c}\text { Emptying time } \\
\text { (minutes) }\end{array}$} & \multicolumn{2}{|c|}{ Number of hips } \\
\hline & $\begin{array}{c}\text { Normal } \\
\text { (13 hips) }\end{array}$ & $\begin{array}{c}\text { Osteoarthritic } \\
\text { (13 hips) }\end{array}$ \\
\hline$<3$ & 7 & 0 \\
\hline$<6$ & 6 & 0 \\
\hline$<12$ & 0 & 2 \\
\hline$<20$ & 0 & 3 \\
\hline$>30$ & 0 & 8 \\
\hline
\end{tabular}

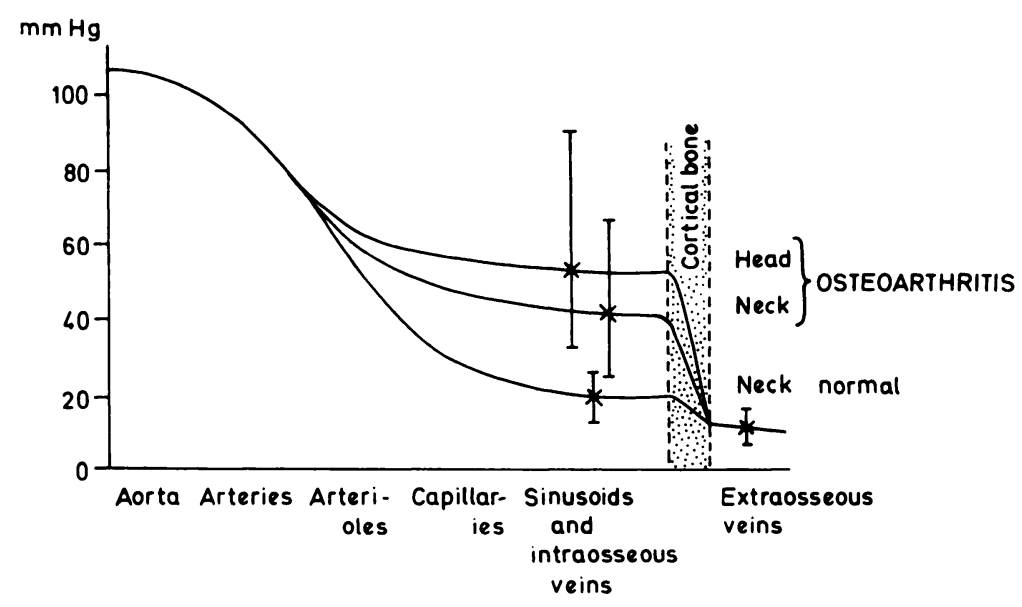

Fig. 13

Schematic representation of intraosseous and extraosseous pressures as observed in the present study.

The pressure tracings obtained from the cancellous bone marrow of the femoral head and neck always showed pulsatile variations synchronous with the pulsations of systemic arteries. If absence of pulsatile pressure is taken as a sign of ischaemia (Arnoldi and Linderholm 1972) our findings in the present study are incompatible with the conception of a state of ischaemia of juxtachondral and subchondral bone of the femoral head in osteoarthritis (Phemister 1940, Cheynel 1947, Pridie 1952).

The fact that the pulse pressure amplitude was higher in the bone marrow of the arthritic hip than in the normal hip is in accordance with the idea that the cancellous bone comprises a "semiclosed space" surrounded by a compact bone layer offering a resistance to outflow of blood that is much higher in osteoarthritis than in normal bone. Characteristically, the pulse pressure amplitude as well as the pressure level fell immediately when osteotomy or fenestration was performed (Arnoldi et al. 1971). It may also be that the cancellous bone of arthritic hips 
offers a greater resistance to flow than normal bone. Pulsatile inflow of blood from ruptured arteries into the pool at the needle tip may then result in greater pressure amplitudes than in normal bone, with a lower resistance to flow of blood from the site of the needle tip. Hyperplastic arteries-with increased lumina-observed by Harrison et al. (1953) in the bone marrow of the arthritic hip may contribute to this result.

The initial stages in the process leading to derangement of the venous drainage from the proximal part of the femur are unknown at present. However, the venous changes seem to be reversible. Phillips, Bulmer, Hoyle and Davies (1967) observed a return to normal or nearly normal morphology in intraosseous phlebographs taken twelve to twenty months after intertrochanteric osteotomy.

Structural changes in cancellous bone-The sometimes pronounced decrease of the arteriovenous pressure difference in the bone tissue caused by the increase of resistance to venous flow from the cancellous bone marrow in the proximal part of the femur (Fig. 13) probably leads to deterioration of the nutritive capillary blood flow. The observation by Hernborg (1969) from radioactive isotope clearance studies of a decrease of the rate of capillary blood flow in the arthritic femoral head supports this conception. Our findings indicate that the changes are more pronounced in the juxtachondral bone of the femoral head than in the neck. It seems possible that this circulatory derangement may be responsible for the well known structural changes of cancellous bone in osteoarthritis, such as alternating zones of necrosis of bone lamellae and signs of osteogenesis, cyst formation and interstitial oedema, as described by Harrison et al. (1953). This hypothesis is strengthened by the findings of Brookes and Helal (1968), who were able to produce structural changes in cancellous bone (coarsening of trabeculation and increased radiodensity) in the femur of adult rats by ligation of the femoral or internal iliac veins. Recently, Arnoldi, Linderholm and Vinnerberg (1972) showed that intermittent intramedullary hypertension, as seen in patients with severe chronic venous insufficiency, may lead to changes in cancellous and compact bone in the skeleton of the ankle region. Two features were characteristic in these patients: apposition of new layers of periosteal bone that appeared-in the vicinity of the ankle joint-as osteophytes, and a mixture of rarefaction and sclerosis of the lamellae of cancellous bone.

Intramedullary hypertension a possible cause of pain in osteoarthritis-Some observations indicate that high intramedullary pressure may be the factor releasing the characteristic aching rest pain of severe osteoarthritis of the hip. Thus, rest pain was present in this study with intraosseous pressure in the femoral neck above $\mathbf{4 0}$ millimetres of mercury but was not observed in patients with pressures below this level.

The injection of contrast material for intraosseous phlebography was done without anaesthesia. Any injection of fluid into a more or less closed space like the medullary cavity will cause a rise of intramedullary pressure (Arnoldi and Linderholm 1972). It was a characteristic finding that while injection of contrast on the non-affected side (with low intramedullary pressure) usually could be done with little discomfort to the patient, even the most careful and protracted injection on the arthritic side immediately caused intense pain, generally spreading from the site of injection along the entire length of the femur. The patients generally recognised this pain as having the same quality as abnormally severe rest pain. This reaction was also noticed by Phillips (1966).

Femoral osteotomy-with or without displacement of the fragments-has been used extensively in the surgical treatment of osteoarthritis of the hip. It is generally agreed that the most spectacular effect of this operation is the almost immediate relief of rest pain. Recently, Arnoldi et al. (1971) showed that intertrochanteric osteotomy caused an immediate fall of intramedullary pressure in the femoral head and neck. Similar results were obtained after denudation of the femoral head in Smith-Petersen cup arthroplasty. These observations indicate that one of the effects of osteotomy is a reduction of intraosseous pressure and support the assumption that rest pain is caused by high intramedullary pressure.

vol. 54 B, No. 3, AUGUST 1972 
The role of vascular changes in the pathology of osteoarthritis-At present we do not know the initial causes of the vascular changes characteristic of clinical osteoarthritis of the hip; nor do we know how early in the process these changes occur. However, it seems possible that some of the more severe signs and symptoms of osteoarthritis may ultimately be consequences of nutritional disturbances of bone adjacent to the joint and intramedullary hypertension. It is important to obtain further information on these points, especially as there are valid indications that the vascular changes may be reversible.

\section{SUMMARY}

1. In fifteen patients with unilateral osteoarthritis of the hip bilateral measurements of the intraosseous pressure of the femoral neck and determination of femoral vein pressure were done simultaneously. These pressure examinations were followed by bilateral intraosseous phlebography of the proximal part of the femur.

2. In a second series of fifteen patients the intraosseous pressures of the femoral head and neck were measured simultaneously before operation for osteoarthritis.

3. The pressure in the femoral vein was equal on the two sides. The intraosseous pressure in the femoral neck was always higher in the arthritic hip than on the unaffected side. In hips with osteoarthritis the pressure in the femoral head was higher than the pressure in the neck. 4. Intraosseous phlebography indicated a state of intramedullary venous engorgement in osteoarthritis. The normal channels for venous drainage from the femoral head and neck were not visible in the phlebographs from the arthritic side. Instead, drainage took place through descending intramedullary vessels to the trochanteric region and down into the femoral shaft. The emptying of intraosseous contrast material from the arthritic hip was delayed.

5. The phlebographs indicated that the abnormally high intraosseous pressure observed in osteoarthritis is caused by a high resistance to flow across the cortex of the proximal part of the femur.

6. The aching rest pain typical of severe osteoarthritis was noted only in patients with intraosseous femoral neck pressure above $\mathbf{4 0}$ millimetres of mercury, an indication that this type of pain is caused by intramedullary hypertension. The decrease of arteriovenous pressure difference, caused by increase of resistance to venous outflow, is probably accompanied by disturbances of nutritive flow. This "venous ischaemia" may play an important role for the structural changes of cancellous bone in osteoarthritis.

This work was supported by the Swedish Medical Research Council (Projects Number B70-17X-2337-03B and B71-17X-2337-04).

\section{REFERENCES}

Arnoldi, C. C., and Linderholm, H. (1966): Intraosseous Pressure of the Calcaneus and Venous Pressure in the Calf of Healthy Human Subjects in the Erect Position. Acta Chirurgica Scandinavica, 132, 646.

Arnoldi, C. C., and Linderholm, H. (1971): Intracalcanean Pressures in Patients with Different Forms of Dysfunction of the Venous Pump of the Calf. Acta Chirurgica Scandinavica, 137, 21.

ARnoldi, C. C., and Linderholm, H. (1972): Fractures of the Femoral Neck. I. Vascular Disturbances in Different Types of Fractures, Assessed by Means of Intraosseous Pressure. Clinical Orthopaedics, in press.

Arnoldi, C. C., Lemperg, R. K., and Linderholm, H. (1971): Immediate Effect of Osteotomy on the Intramedullary Pressure of the Femoral Head and Neck in Patients with Degenerative Osteoarthritis. Acta Orthopaedica Scandinavica, 42, 25.

Arnoldi, C. C., Linderholm, H., and Vinnerberg, A. (1972): Skeletal and Soft Tissue Changes in the Lower Leg in Patients with Intracalcanean Hypertension. Acta Chirurgica Scandinavica, 138, 25.

Azuma, H. (1964): Intraosseous Pressure as a Measure of Haemodynamic Changes in Bone Marrow. Angiology, 15, 396.

Brookes, M., and Helal, B. (1968): Primary Osteoarthritis, Venous Engorgement and Osteogenesis. Journal of Bone and Joint Surgery, 50-B, 493. 
Cheynel, J. (1947): Recherches sur la physio-pathologie de la hanche. Revue d'Orthopedie, 33, 7.

Goldhaft, A. D., Wright, L. M., and Pemberton, R. (1930): The Production of Hypertrophic Arthritis by Interference with the Blood Supply. American Journal of the Medical Sciences, 180, 386.

Harrison, M. H. M., Schajowicz, F., and Trueta, J. (1953): Osteoarthritis of the Hip: A Study of the Nature and Evolution of the Disease. Journal of Bone and Joint Surgery, 35-B, 598.

Helal, B. (1962): Osteoarthritis of the Knee. Thesis. University of Liverpool.

HernBorg, J. (1969): Elimination of $\mathrm{Na}^{131} \mathrm{I}$ from the Head and the Neck of the Femur in Unaffected and Osteoarthritic Hip Joints. Arthritis and Rheumatism, 12, 30.

Mériel, P., Ruffié, R., and Fournié, A. (1955): La Phlébographie de la hanche dans les coxarthroses. Revue de Rhumatisme et des Maladies Ostéo-articulaires, 22, 238.

Phemister, D. B. (1940): Changes in Bones and Joints Resulting from Interruption of Circulation. Archives of Surgery, 41, 455.

Phillips, R. S. (1966): Phlebography in Osteoarthritis of the Hip. Journal of Bone and Joint Surgery, 48-B, 280.

Phillips, R. S., Bulmer, J. H., Hoyle, G., and Davies, W. (1967): Venous Drainage in Osteoarthritis of the Hip. Journal of Bone and Joint Surgery, 49-B, 301.

Pridie, K. H. (1952): The Development of Osteoarthritis of the Hip Joint. Journal of Bone and Joint Surgery, 34-B, 153.

Susse, H. J. (1956): Der enossale Druck. Zeitschrift der Gesamte Innere Medizin, 11, 219.

Warde, E. N. (1964): Osteotomy of the Tibia and Fibula in the Treatment of Chronic Osteoarthritis of the Knee. Postgraduate Medical Journal, 40, 536.

Wollenberg, G. A. (1909): Die Ätiologie der Arthritis deformans im Lichte des Experimentes. Archiv für Orthopädie, Mechanotherapie und Unfallchirurgie, 7, 226.

VOL. 54 B, NO. 3, AUGUST 1972 